\title{
SOCIAL NORMS OF COORDINATION AND COOPERATION - ERRATUM
}

\section{By GERRY MACKIE}

In the original publication of this article, four matrices appeared incorrectly on pages $88,90,90$, and 95 , respectively. ${ }^{1}$ Corrected versions of these matrices appear below:

First matrix, p. 88 in original article:

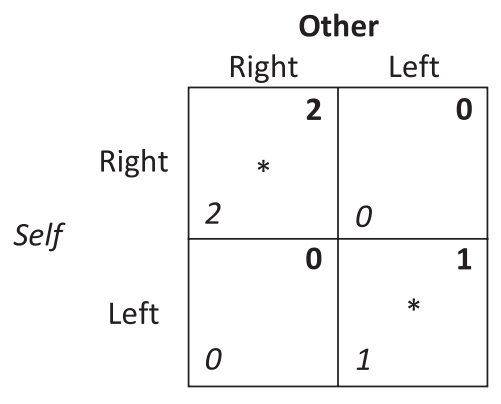

Second matrix, p. 90 in original article:

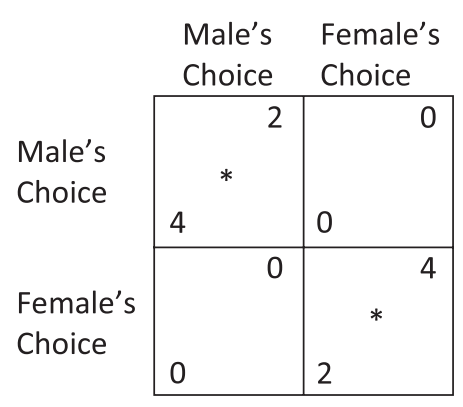

\footnotetext{
${ }^{1}$ Gerry Mackie, "Social Norms of Coordination and Cooperation," Social Philosophy and Policy 35, no. 1 (2018): 77-100. doi: 10.1017/S0265052518000109 
Third matrix, p. 90 in original article:

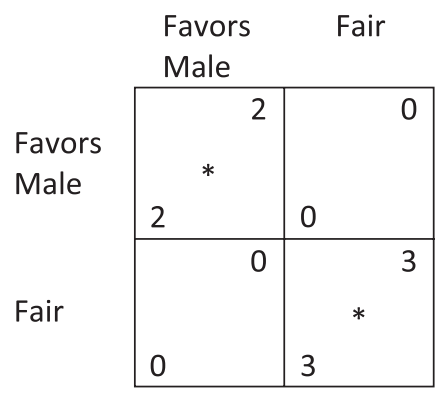

Fourth matrix, p. 95 in original article:

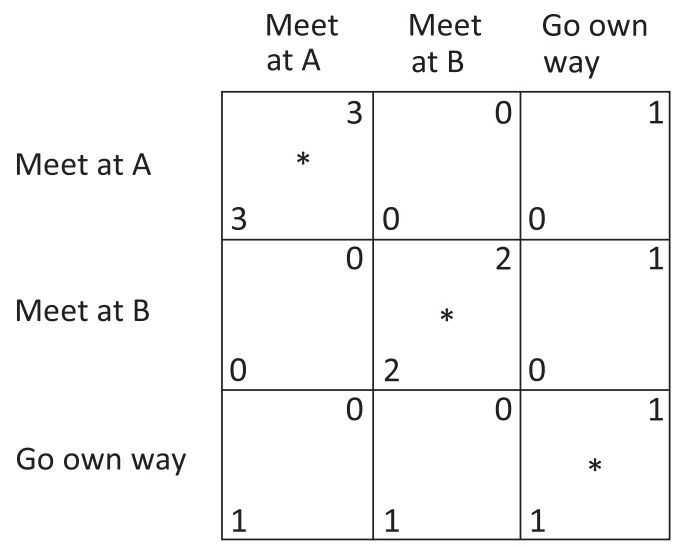

The editors of Social Philosophy and Policy would like to convey to the author their sincere regrets for the errors in the original publication of the article. 